\title{
La forma correcta de utilizar la ecuación de Bernoulli
}

\section{The correct way to use Bernoulli's equation}

Recibido: mayo 12 de 2019 | Revisado: junio 17 de 2019 | Aceptado: julio 11 de 2019

Luis A. Arriola ${ }^{\mathrm{I}}$

1 Universidad de San Martín de Porres, Lima - Perú

larriola@usmp.pe

\begin{abstract}
Resumen
La ecuación de Bernoulli es un caso determinado de un problema del flujo de fluido. Se deben cumplir algunas restricciones para aplicar correctamente esta ecuación en particular. El flujo del fluido debe considerarse no viscoso, incompresible, estable e irrotacional. Sin embargo, si el flujo del fluido es rotacional, la ecuación de Bernoulli aún puede aplicarse siempre y cuando los puntos de interés estén en la misma línea de corriente del flujo. Aquí, nos enfocaremos en demostrar que, en el caso de un flujo de fluido rotacional, los puntos de interés deben encontrarse en la misma línea de corriente del flujo y por esta razón, sí se podría continuar con el uso de la ecuación de Bernoulli. El principio solo es aplicable a los flujos isentrópicos: cuando los efectos de los procesos irreversibles (e.g. turbulencia, fricción) y los procesos no adiabáticos (e.g. la radiación de calor, difusión de masa) son pequeños y pueden despreciarse.
\end{abstract}

Palabras clave: flujo, Bernoulli, viscoso, incompresible, estable, irrotacional, línea de corriente, isentrópico, irreversible, turbulencia, fricción

\begin{abstract}
Bernoulli's equation is a certain case of a fluid flow problem. Some restrictions must be met in order to correctly apply this particular equation. The fluid flow must be considered inviscid, incompressible, steady and irrotational. However, if the fluid flow is rotational, Bernoulli's equation can still be applicable as long as the points of interest are on the same streamline of the fluid flow. Here, we will focus on demonstrate that, in the case of a rotational fluid flow, the points of interest must be on the same streamline and because of that, it can be proceeding with the usage of Bernoulli's equation. The principle is only applicable for isentropic fluid flows: when the effects of irreversible processes (e.g. turbulence, friction) and non-adiabatic processes (e.g. heat radiation, mass diffusion) are small and can be neglected.
\end{abstract}

Key words: fluid, Bernoulli, inviscid flow, incompressible, steady, irrotational, streamline, isentropic, adiabatic, turbulence, friction

(C) Los autores. Este artículo es publicado por la Revista Campus de la Facultad de Ingeniería y Arquitectura de la Universidad de San Martín de Porres. Este artículo se distribuye en los términos de la Licencia Creative Commons Atribución No-comercial - Compartir-Igual 4.0 Internacional (https://creativecommons.org/licenses/ CC-BY), que permite el uso no comercial, distribución y reproducción en cualquier medio siempre que la obra original sea debidamente citada. Para uso comercial contactar a: revistacampus@usmp.pe. 


\section{Inroduction}

Various forms of Bernoulli's equation can be modeled because of the existence of various types of fluid flow, and therefore Bernoulli's principle can be applied too. Bernoulli's principle states that, an increase in the speed of a fluid flow occurs simultaneously with a decrease in internal pressure. The principle is named after Daniel Bernoulli published it in his book Hydrodynamic in 1738. Although, Bernoulli deduced that pressure decreases when the flow speed increases, it was Leonhard Euler who derived Bernoulli's equation in its usual form in 1752. All in all, there is a correct way of using Bernoulli's equation with confidence and which is briefly described to continuation.

The law that explained the phenomenon from the energy conservation point of view was found in his Hydrodynamic work. Later, Euler deduced an equation for an inviscid flow (assuming that viscosity was insignificant) from which Bernoulli's equation arises naturally when considering a stationary case subjected to a conservative gravitational field.

\section{Discussion}

To arrive at Bernoulli's equation, certain assumptions had to be made which limit us the level of applicability. According to Euler equation Eq. 1, defined by Anderson, Jr. (1989), it gives the variation of pressure with respect to speed variation, ignoring shear forces (inviscid fluid flow) and body forces (weight of the air fluid particle is ignored). Only pressure forces were considered.

$$
d p=-\rho v d v
$$

Integrating Eq. (1) by using a limit integration and considering an incompressible fluid flow (change in density is very small because of low speed), will give us Bernoulli's equation applicable to points 1 and 2 which are on the same streamline. However, if the flow is uniform throughout the field, then the constant in Eq. (2) is the same for all streamlines as defined by Anderson, Jr. (1989).

$$
\begin{gathered}
\int_{P_{1}}^{P_{2}} d p=-\rho \int_{V_{1}}^{V_{2}} V d v \\
P_{2}-P_{1}=\frac{-1}{2} \rho\left(V_{2}^{2}-V_{1}^{2}\right) \\
P_{1}+\frac{1}{2} \rho V_{1}^{2}=P_{2}+\frac{1}{2} \rho V_{2}^{2}=\begin{array}{c}
\text { const along } \\
\text { streamline }
\end{array}
\end{gathered}
$$

The assumptions that were made during the derivation of this equation led us to some restrictions that must be implemented in order to use Bernoulli's equation. But, first of all, we must verify if the flow field in question is possible to exist. This is done by verifying if continuity equation is fulfilled.

\section{Continuity Equation in its vector form}

The continuity equation states that, "the net outflow of mass through the surface surrounding the volume must be equal to the decrease of mass within the volume" (Bertin and Smith 1998 , p. 24). This is, when a fluid is in motion, it must move in such a way that mass is conserved as it is stated in Eq. 3 defined by Bertin and Smith (1998):

$$
\frac{\partial \rho}{\partial t}+\nabla(\rho \overrightarrow{\boldsymbol{V}})=0
$$


Where $\overrightarrow{\boldsymbol{V}}$ is the fluid density, $\mathrm{t}$ is the time, is the flow velocity vector field.

\section{Steady flow}

To see further how mass conservation places restrictions on the velocity field, consider a steady fluid flow. That is, for a relatively low speed flow, the pressure variations are sufficiently small, and because of this, the density change is also small that can be assumed to be constant and so, the density of the fluid flow does not vary with time.

$$
\frac{\partial \rho}{\partial t}=0
$$

\section{Incompressible}

Since density change is very small for low velocity airflows, it can be assumed to be constant. One way to proof this, is by verifying if we are dealing with low velocity airflows. As a rule of thumb, if its mach number is lower than 0,3 or has a velocity less than 300 $\mathrm{ft} / \mathrm{s}$ or $100 \mathrm{~m} / \mathrm{s}$ (or approximately 200 $\mathrm{mph}$ ), then the velocity airflow can be assumed to be small and treated as incompressible Anderson, (1989) and Anderson (2003):

$$
M=\frac{V}{a}=\frac{V}{\sqrt{\gamma R T}}
$$

Where:

$\mathrm{V}$ is the flow velocity a is the Speed of Sound

$\mathrm{T}$ is the temperature of the flow field $Y$ is the ratio of the specific heats at constant pressure and volume respectively and has a value of $Y=1.4$ for dry air.

$\mathrm{R}$ is the air constant for ideal gas and has a value of:

$$
R=1716 \frac{f t . l b}{\text { slugs. }} \quad \text { or } \quad R=287 \frac{\text { N.W }}{\text { Kg.K }}
$$

Then, so far, the continuity equation reduces to:

$$
\nabla \cdot \vec{V}=0 \quad \text { or: } \quad \frac{\partial u}{\partial x}+\frac{\partial v}{\partial y}+\frac{\partial w}{\partial z}=0
$$

4. Remember that shear forces (friction) and body forces (gravity) were ignored to get Eq. (1). But in the case where conservative body forces are considered like gravity, Bernoulli's equation would include an extra term $\rho g h$ as shown in Eq. (5). In many applications of Bernoulli's equation, the change in the term pgh (change in potential energy) along the streamline flow is so small in comparison to the other terms that it can be ignored. For example, in the case of an aircraft in flight, the change in height " $h$ " along a streamline flow is so small that the term pgh can be disregarded.

$$
\begin{aligned}
& \frac{1}{2} \rho V^{2}+P+\rho g h=\text { const } \\
& \frac{1}{2} \rho V^{2}+P=\text { const }=P_{\text {total }}
\end{aligned}
$$

where

Static pressure $=\mathrm{P} \quad \frac{1}{2} \rho V^{2}$

Dynamic pressure $=$

Total Pressure $=$ Ptotal

\section{Inviscid Flow}

The product of viscosity times shear velocity gradient defines the term shear stress. We must understand that, there are no real fluids for which viscosity is zero. But, there are many real cases where this product is sufficiently small that, the shear stress term, can be ignored when compared to other terms in the governing equations as described by Bertin and Smith (1998). 


\section{Irrotational flow.}

If the 2D flow contains no singularities, then the Vorticity Vector in Eq. (6) for irrotational flow must be zero as defined by Bertin and Smith (1998).

$$
\begin{gathered}
\overrightarrow{\boldsymbol{\omega}}=\boldsymbol{\nabla} \times \overrightarrow{\boldsymbol{V}}=\left(\boldsymbol{i} \frac{\partial}{\partial x}+\boldsymbol{j} \frac{\partial}{\partial y}\right) \times(\boldsymbol{i} u+\boldsymbol{j} v)=\mathbf{0} \\
\boldsymbol{\nabla} \times \overrightarrow{\boldsymbol{V}}=\left(\frac{\partial v}{\partial x}+\frac{\partial u}{\partial y}\right) k=\mathbf{0} \\
\text { or } \\
\boldsymbol{\omega}=\frac{\partial v}{\partial x}-\frac{\partial u}{\partial y}=0
\end{gathered}
$$

If $\omega=0$ (irrotational flow), then the constant in Eq. (2) is real in all the fluid flow. But if $\omega \neq 0$ (rotational flow), then, this constant is only real along a streamline. Here, we present an example of the correct way of using Bernoulli's equation.

Let' me consider a $2 \mathrm{D}$ velocity flow field at sea level $\quad\left(\rho=1.225 \frac{\mathrm{Kg}}{f t^{3}}\right)$ and defined by:

$$
\begin{aligned}
& u=x^{2}-x y \\
& v=\frac{y^{2}}{2}-2 x y
\end{aligned}
$$

Where " $u$ " and " $v$ " are defined in $\mathrm{m} / \mathrm{s}$.

First, we need to identify if continuity equation is satisfied, or in other words, if the velocity flow field is possible to exist.

Continuity equation in a $2 \mathrm{D}$ form is:

$$
\begin{array}{ll} 
& \frac{\partial u}{\partial x}+\frac{\partial v}{\partial y}=0 \\
\text { Then, } & \frac{\partial u}{\partial x}=2 x-y \\
\text { and } & \frac{\partial v}{\partial y}=y-2 x
\end{array}
$$

Substituting equations (11) and (12) into Eq. (10), yields:

$$
2 x-y+y-2 x=0
$$

Eq. (13) shows that the given flow velocity field satisfy the continuity equation. Second, we need to find out if the given flow velocity field is rotational or irrotational.

Evaluating the partial derivatives of equations (8) and (9) yield equations (14) and (15) respectively.

$$
\begin{gathered}
\omega=\frac{\partial v}{\partial x}-\frac{\partial u}{\partial y} \\
\frac{\partial v}{\partial x}=-2 y \\
\frac{\partial u}{\partial y}=-x
\end{gathered}
$$

Substituting equations (14) and (15) into Eq. (7) yields:

$$
\omega=-2 y-(-x)=x-2 y \neq 0
$$

It is clear that, the given velocity flow field is rotational. So, that means that we can still use Bernoulli's eq. only if the two given points are on the same streamline. So, we need to identify the streamline by using the 2D streamline Eq. (16) defined by Bertin and Smith (1998):

$$
\frac{d x}{u}=\frac{d y}{v}
$$

Solving this equation for the given velocity components shown in equations (8) and (9) one finds that

$$
\begin{gathered}
\frac{d x}{x^{2}-x y}=\frac{d y}{\frac{y^{2}}{2}-2 x y} \\
\text { and } \\
\left(\frac{y^{2}}{2}-2 x y\right) d x-\left(x^{2}-x y\right) d y=0
\end{gathered}
$$

Since this equation is a point function, then

$$
d \varphi=\frac{\partial F}{\partial x} d x-\frac{\partial F}{\partial y} d y=0
$$




$$
\begin{gathered}
\text { where } \\
\frac{\partial F}{\partial x}=v=\frac{y^{2}}{2}-2 x y \\
\text { and } \\
\frac{\partial F}{\partial y}=-u=-\left(x^{2}-x y\right)
\end{gathered}
$$

Integrating Eq. (17) with respect to “ $x$ " yields

$$
\varphi=F=\frac{y^{2}}{2} x-x^{2} y+f_{(y)}
$$

Where $\varphi=F$ is the respective stream function

Then, taking the derivate of Eq. (19) with respect to " $y$ " yields

$$
\frac{\partial F}{\partial y}=y x-x^{2}+f^{\prime}(y)
$$

Replacing Eq. (20) into Eq. (18) yields

$$
\begin{gathered}
-x^{2}+x y=y x-x^{2}+f^{\prime}(y) \\
f^{\prime}{ }_{(y)}=0
\end{gathered}
$$

Therefore; $f_{(y)}=$ const and the streamline is:

$$
\varphi=\frac{y^{2}}{2} x-x^{2} y+\text { const }=0
$$

Now, if we intend to use Bernoulli's equation, for example to find the static pressure difference between two points in the flow, we must be sure to have these two points on the same streamline. Consider these two points to be: $(-1,2)$ and $(2,2)$. The coordinates of these two points are defined in meters. in -4 .

For point one $(-1,2)$, Eq. (21) results

$$
\frac{(2)^{2}}{2}(-1)-(-1)^{2}(2)=-4
$$

For point two $(2,2)$, Eq. (21) also results in -4

$$
\frac{(2)^{2}}{2}(2)-(2)^{2}(2)=-4
$$

Then, these two points are on the same streamline, so we can use Bernoulli's equation only between these two points even though the flow is rotational. Now, using Eq. (8) and (9)

$$
\begin{aligned}
& u=x^{2}-x y \\
& v=\frac{y^{2}}{2}-2 x y
\end{aligned}
$$

For point one $(-1,2)$

$$
\begin{gathered}
u=(-1)^{2}-(-1)(2)=1-(-2)=3 \mathrm{~m} / \mathrm{s} \\
v=\frac{(y)^{2}}{2}-2(x)(y)=\frac{(-1)^{2}}{2}-2(-1)(2)= \\
\frac{1}{2}-2(-2)=\frac{1}{2}+4=\frac{9}{2}=4.5 \mathrm{~m} / \mathrm{s} \\
\quad V_{1}=\sqrt{(3)^{2}+(4.5)^{2}}=5.41 \mathrm{~m} / \mathrm{s} \\
\text { For point two }(2,2) \\
u=(2)^{2}-(2)(2)=4-4=0 \mathrm{~m} / \mathrm{s} \\
v=\frac{(2)^{2}}{2}-2(2)(2)=2-8=-6 \mathrm{~m} / \mathrm{s}
\end{gathered}
$$

(negative sign means opposite direction)

$$
V_{2}=\sqrt{(0)^{2}+(-6)^{2}}=6 \mathrm{~m} / \mathrm{s}
$$

Using Bernoulli`s Eq. (2):

$$
\begin{gathered}
P_{1}+\frac{1}{2} \rho V_{1}^{2}=P_{2}+\frac{1}{2} \rho V_{2}^{2} \\
P_{1}+\frac{1}{2} * 1.225 * 5.41^{2}=P_{2}+\frac{1}{2} * 1.225 * 6^{2} \\
P_{1}-P_{2}=4.123 P a
\end{gathered}
$$

The static pressure difference between and which are located on the same streamline in the fluid flow is Pa. 


\section{Conclusion}

Throughout this paper, the correct way of using Bernoulli's equation has been shown. Initially, it has been presented some assumptions for which this equation is valid to apply. These assumptions led to a set of restrictions that must be met in order to apply correctly this equation.
However, during the process of the application of Bernoulli's equation, the analyst has to be sure which restrictions apply for the particular case. According to this, the results must be presented in a similar way as it was done in this paper like the pressure difference between the two points on the same streamline.

\section{References}

Anderson, Jr, J.D. (1989). Introduction to Flight. 3rd ed. New York: McGrawHill.

Anderson, Jr. J.D. (2003). Modern Compressible Flow with Historical
Perspective. $2^{\text {nd }}$ ed. New York: McGraw-Hill.

Bertin, J.J. and Smith, M.L. (1998). Aerodynamics for Engineer. 3rd ed. New Jersey: Prentice Hall. 